\title{
Decentralisation in Macedonia's health system: a consultancy report
}

\begin{abstract}
This article examines two quite different shapes of decentralisation programme in Macedonia: GPs and the established system of health centres in the country; and in its hospital sector. Focusing extensively on the policy options for decentralisation, in particular around the opportunities for local self-government, the article focuses on how decentralisation may be made to work to improve the health system and health care services offered in Macedonia. Recognising that the reforms are likely to have only minimal impact on the overall level of resources available within the health system, the article identifies the areas where there is nevertheless likely to be some beneficial shifts. The article concludes by setting out the areas in which the Ministry of Health needs to develop and strengthen its regulatory activities as well as its overall capabilities.
\end{abstract}

Keywords: Macedonia, decentralisation, health system reform, health centres, local self-government, municipal administration, policy-making frameworks, hospital decentralisation.

\section{Introduction}

The central challenge facing the Macedonian health care system is how to harness the potential power of decentralisation as a means to help achieve existing Ministry objectives for the Macedonian health care system. Decentralisation needs to be designed such that it does not interfere with, or weaken, the ability of Macedonia to achieve the goals of its central health system. A major issue will be ensuring that decentralisation does not increase inequities in access to necessary services and/or in the quality of services received between different localities or between different population groups.

The current proposed decentralisation in the health sector is in outpatient services - primary, outpatient specialist and emergency care - provided in the health centres located in many municipalities in Macedonia.

A series of related questions can be asked about how this proposed new decentralisation plan should work:

a. can decentralisation in the health sector learn from the ongoing experience with decentralisation in the education sector in Macedonia? Several relevant points emerge from how education has been handled:

- national control was maintained over the content of the service - in the case of education, of the curriculum taught and the test standards for satisfactory completion by students

- local control over the administration and management of schools was created, with the schools being transferred into local municipal hands 
- school governing boards were created which had to approve local budgets and hiring decisions

a selection of the school headteacher was vested in the municipal mayor; however, the governing board presented the mayor with the name of a single qualified candidate, who had to meet nationally-established selection criteria in terms of education and direct managerial experience. If the mayor rejected this first candidate, the governing board would name a second candidate who, even if rejected by the municipal major, still takes office

b. how can the municipalities be encouraged to help make decentralisation in the health sector successful? Macedonian municipalities have a strong desire to increase their overall governmental role. This desire is supported by the Law on Local Self-Government of 2002, which was passed in part to ensure that the interests of Macedonia's ethnic groups were met. It also has an historical dimension in that, during the Tito period, a smaller number of somewhat larger municipalities (34 rather than the current 86) helped fund the building of the health centres in their municipalities and had a major role in running them as part of the then-current concept of municipal self-management

c. can the proposed decentralisation of the health centres be structured in a manner that is able to minimise the constant disputes between municipalities and the national government over the adequacy of national funds transferred to the municipalities for this purpose? Such disputes have created an ongoing distraction regarding the decentralisation of educational responsibilities

d. can the proposed decentralisation of the health centres to the municipalities be structured to reinforce and strengthen the ongoing privatisation of primary care physicians and of their offices inside the health centres? Decentralisation offers a major opportunity to the Ministry to structure the future relationship between the municipalities and the newly-private general practitioners

e. can decentralisation in the health sector take advantage of the training programmes that UNDP and USAID have run for municipalities in the areas of fiscal management and local administrative control? Can the new health sector decentralisation synchronise its approach to municipal responsibilities so that the Ministry of Health requirements can build on the existing management control systems that these two international agencies have helped develop and put into place?

f. can the proposed decentralisation of the health centres be structured to help reduce the rates of unnecessary referrals from primary care to hospitals (both emergency and outpatient specialist services)? Can the outcome of the new relationship between the municipally-run health centres and private general practitioners be one in which patients are encouraged to visit them and also one in which they are more willing to receive more health services from their GP (by creating an inviting environment in the health centres, ensuring good building cleaning and maintenance, etc)?

g. can the Ministry strengthen existing monitoring and evaluation personnel to ensure that the municipalities conform to the terms of the signed contracts for operating the health centres? Decentralisation requires stronger regulation and enforcement than does direct ownership of health facilities, with well-trained and well-motivated inspectors so as to ensure compliance by independent municipal decision-makers. 


\section{Analytical framework}

There are two theoretical frameworks that can help assess the value of particular decentralisation-based strategies. One is to de-construct decentralisation into three separate components:

- political/policy decentralisation

- administrative decentralisation

- fiscal decentralisation.

National policy-makers have the ability to decide whether to adopt decentralisation in each of these three different sub-sectors and then, separately, to decide how much decentralisation they prefer in each one. For example, even countries like Sweden, which has a long history of strongly-decentralised administrative decision-making in its health system, only decentralise a portion of the political/policy decisions, keeping the most important ones as national policy-making responsibilities (typically, to ensure equity across the different decentralised regions and also to maintain a consistent national policy in politically important areas).

A second theoretical framework (taken from the new book Decentralization in Health Care from the European Observatory) sets out three tests that national policymakers can use to assess whether a particular decentralisation strategy (using one or more of the three forms of decentralisation just noted) satisfies the expected goals and objectives. The three tests are:

- does it improve health system performance?

- does it enhance governmental legitimacy?

- does it restrain self-interested behaviour by health care institutions and personnel?

A good decentralisation policy should be able to satisfy each of these three important criteria.

\section{Political context at municipal level}

Municipal governments, both individually and as a part of the Association of the Units of Local Governments of Macedonia (ZELS), want to be consulted about health care issues. This is consistent with the language in Article 22 of the Law on Local Self-Government of 2002, which calls for municipal representation on locally-relevant governing bodies in the health sector. They also are interested in proposals by the government to take over the administrative management of the health centres, which the municipalities see as important politically in meeting the needs of their constituencies and which also they perceive to be a potential source of new revenue.

However, the municipalities are cautious about taking on health sector responsibilities, especially in the area of care provision. They are still trying to digest their newly-acquired management responsibilities in the education sector and worry that health care is too large and too expensive for them to be able to manage it effectively. Yet, they want better quality health services to be provided for their inhabitants and some municipalities would like to shift some resources currently going to primary care into needed specialised services.

\section{Decentralisation in primary care}

The current reform structure is that, as of 1 January 2007, GPs have become private contractors, paid on a per capita basis under contracts with the Health Insurance 
Fund. As part of this new arrangement, GPs will be expected to pay rent for their offices in the health centres. The national government has proposed that the physical buildings of the health centres - not the medical activities that take place within them - will be turned over to municipal management.

a. This appears to be a good mix of:

1. the national (centralised funding; centralised responsibility for clinical content) and the local (decentralised administration of the physical infrastructure); and also

2. public roles (financing, clinical monitoring and supervision, municipal management of buildings) and private ones (GPs, GPs' offices and equipment).

b. A key policy concern is how well the municipalities will manage the health centres. Central points include:

1. ensuring that the health centre retains its main purpose as a location for health services

2. ensuring that municipalities do not drive GP rents so high that GPs are forced out

3. ensuring that the health centre is well-maintained and well-managed (and not just a municipal 'cash cow' to be milked).

c. Possible policy options to protect health centres during the transfer period include:

1. requiring each municipality to apply to the Ministry to take over its health centre, presenting a 'business plan' for how it will be managed (operating costs; rental rates for the first three years; proposed use of empty space; etc)

2. requiring each municipality to have an individually-signed contract with the Ministry, specifying that the business plan will be followed and also that it will be updated every three years in a new contract

3. the contract will specify that the health centre must always keep - say $-60 \%$ of its floor space for health care purposes

4. the contract will specify that rents to private GPs (and medical specialists in the future if they are also privatised) have a maximum rate of $x \%$ (say, 20\%?) of that individual doctor's total Health Insurance Fund capitation payment each month, as long as the GP has over $y$ (say, 200) patients on his/her list after one year (this enables the municipalities to encourage GPs with only a few patients to leave, freeing office space for other medical purposes)

5. the contract will establish a governing board for the health centre, to be composed of key local personnel as well as a Ministry representative, which will have the responsibility for final approval of the annual operating budget for the municipally-run health centre

6. if the terms of the contract are violated, then negotiations are mandated but (like Germany with its sickness funds) the Ministry reserves the right to take over the health centre and administer it until a new contract with the municipality is negotiated and signed.

d. the transfer of the health centres will have a three-year roll-out period. Only a few well-run municipalities will be given signed contracts in the first year, based on the quality of the business plans they submit. Each year, a number of additional 
municipalities will be given contracts, again based on their business plan and the quality of their management personnel and systems (similar to the UK and Spanish approaches in the past)

e. regarding efforts to reduce unnecessary/expensive primary care referrals from GPs to hospitals, the Health Insurance Fund could provide incentives to private GPs with the appropriate equipment to do more of the work themselves (monitoring diabetic patients; setting simple finger fractures; etc). Possible mechanisms to accomplish this could include:

1. a multi-part pay structure (like payments in the UK from the National Health Service to private GPs - part-capitation; part fee-for-services for certain preventive and/or also curative acts)

2. tax incentives to buy new medical equipment necessary for their private offices

3. a one-off equipment and refurbishment allowance.

\section{Decentralisation in the hospital sector}

The hospital sector in Macedonia does not currently present an attractive management possibility to the municipalities. Moreover, most municipalities presently do not have adequate managerial personnel or expertise to take on the additional burden of managing hospitals. Lastly, as the Director of the Health Insurance Fund has stressed, hospitals present a much greater danger, if they are inadequately managed, of building up high debt levels that will require substantial additional funds from the national level (a financial dilemma that primary care generally does not present).

Given this context, the most appropriate form of decentralisation for the hospital sector would appear to be one that is similar in general structure to that put in place by the NHS in the UK in the 1990s. This reform involved transforming each hospital into a semi-independently managed public body (which in the UK since 1991 has been termed a 'self-governing trust'). This form of what is often termed new public management creates clear administrative decentralisation, but it does so inside the public sector (e.g. no privatisation) and, indeed, within the national level of authority (no role for the local authority in this process). This process will have to be sensitive to the need to build up the capacity of public sector hospitals in Macedonia to enable them to compete on a more equal basis with the two private hospitals that have already been set up in Skopje. It also needs to strengthen and reinforce the recent change in the law, requiring publicly-employed medical specialists to pursue their after hours private medical activities within public hospitals rather than moving over to private profit-making institutions.

A number of financial and managerial reforms ought to be considered as part of this process. Each hospital (as in the UK) could be required to file a 'business plan' with the Ministry, specifying how it would provide services and how it would obtain adequate funds to pay for these. These business plans would become the basis for a fixed-year contract between the hospital and the Ministry, specifying exactly how the hospital would proceed. This contract-based creation of independently-managed public bodies would be rolled out over a three-year period. In the first year, only a few of the best-managed hospitals which presented strong business plans would be given contracts by the Ministry. This process would then be expanded over the next two years such that, after three years, all hospitals would be managed on a contract basis. 
Among additional key points to consider are the following:

- hospitals would be paid on a case-based/diagnosis-related group (DRG) basis, with physicians and other personnel paid by the hospital out of these case-based funds (i.e. salaries would not be paid, as they are at present, directly by the Health Insurance Fund)

- each hospital would have its own governing board, appointed from knowledgeable local individuals as well as a representative of the Ministry, which would have to approve major budget and personnel decisions

- hospital managers would have a limited (and specified) freedom to adjust the medical services offered, as well as to hire and fire personnel.

\section{Impact on available revenues}

These two decentralisation programmes - for GPs and the health centres; and for hospitals - are likely to have only a minimal impact on the overall level of resources available to the health sector in Macedonia. Instead, the main financial impact would be on the reallocation of existing resources, especially among GPs and hospitals. Municipalities would also gain financially as they would benefit if they ran the health centres in an efficient manner.

This minimal impact on the overall resources available within the health sector reflects the role of the Health Insurance Fund (HIF) as the central determinant of the overall level of resources available. The HIF allocates a large proportion of the existing national funds available for health services. The HIF is also responsible for reducing 'leakage' - where employers do not pay the HIF the full amount owed for all their employees (the Director of the HIF estimates that an additional $20 \%$ could be obtained if existing levels of leakage could be stopped) - and thus for ensuring that additional, owed resources are, in fact, captured for use by the health system.

However, the decentralised structure contemplated in this report is likely to create three areas where the total amount of resources would shift around somewhat - two at the primary care level and one at the hospital level. In primary care, more popular GPs with larger lists, by virtue of the capitation-based payment system, would increase their overall revenues. These successful GPs would do so by, in effect, taking funds from GPs who had smaller patient lists. No new money would be raised by this process, but the flow of existing funds would be altered with the more successful GPs earning additional amounts that would enable them to expand their services - perhaps to hire an additional nurse or purchase new diagnostic equipment. The second manner in which primary care funds would be re-allocated involves the payments to the municipalities (typically, rents from the now-privatised GPs) for the management of the health centres.

At the hospital level, publicly-owned hospitals which became public companies could have a number of opportunities to increase their available revenues:

- better-run, higher-quality hospitals could gain additional contracts for services to patients that had previously gone to other hospitals

- hospitals operating as semi-independently managed public companies could contract out space at the entrance to the hospital to small businesses - flower shops or small cafeterias - which would pay them rent (or even a percentage of their earnings) 
- the better-run hospitals operating as public companies might succeed in attracting back to the public sector some patients who currently receive their care in the two private hospitals in Skopje, thereby building revenues and services inside public sector institutions.

\section{Drawing the strands together}

Decentralisation can be useful as a tool to help the Ministry of Health in Macedonia implement its major health reform strategies. However, decentralisation in the health sector is different in structure and character than the issue of the decentralisation to local municipal governments of administrative functions generally. Instead, decentralisation in regard to health-related activities needs to be viewed as part of a balance between the centralised and decentralised functions necessary to run an effective and efficient healthcare system in which the allocation of particular functions (political/ policy making, administrative and fiscal) is based on the inherent nature of the particular medical service, the importance of co-ordination among different medically-related actors (e.g. primary care and hospitals), the managerial capacity of local governments and the impact of decentralisation on overall health care costs and efficiency.

The Ministry of Health in Macedonia has begun to shape two quite different types of decentralisation strategy for use in the health sector. In primary care, GPs have been shifted into the private sector and the health centres where they practise are in the process of being transferred to local municipal management. In the hospital sector, plans are underway to transform hospitals into independently-managed public companies which will remain owned by, and ultimately accountable for their performance to, the Ministry. Both models of decentralisation involve substantial amounts of administrative decentralisation inside the health care sector and will therefore require increased levels of regulatory activity by the Ministry:

- stipulating the conditions for decentralised administrations which guarantee that overall national health sector objectives are met (equity of access and treatment; efficient use of resources)

- evaluating the business plans of municipalities (to manage the health centres) and of hospitals (to become public companies)

- monitoring performance once contracts are signed; and

- assessing overall compliance before existing contracts are renewed.

\section{Next steps}

Implementation of this two-part approach to health care provision in Macedonia suggests that the Ministry may want to develop and/or strengthen its capabilities in three key areas of activity:

1. a contracts capability, firstly to assess the quality of submitted business plans and then to negotiate agreements both with municipal governments (health centres) and with individual hospital managements; as well as subsequently to monitor the level of compliance of both municipalities and hospitals with the terms of these agreements

2. a training capability to work with the hospital managements selected to become public companies to ensure that they are capable of the necessary decision-making processes 
3. an information technology capability to ensure that the appropriate information collection systems are in place to enable the Ministry's contracts unit adequately to monitor the compliance of municipalities and hospitals with the signed agreements.

The WHO Regional Office for Europe could support this ongoing process in Macedonia with additional technical assistance. Particularly helpful would be expertise from Norway or the UK in the negotiation and writing of contracts for the transfer of hospitals to a public company basis of operations. 